\author{
Martina NOVOTNÁ, PhD \\ E-mail: martina.novotna@vsb.cz \\ Department of Finance \\ VSB - Technical University of Ostrava
}

\title{
THE IMPACT OF INDUSTRY AND BUSINESS ENTITY TYPE ON CORPORATE SURVIVAL
}

\begin{abstract}
The probability of corporate bankruptcy is typically analysed on the basis of credit score models, which are statistically derived models for the prediction of credit risk.If the dependent variable is time to bankruptcy, we can use the methods of survival analysis. The main objective of this article is to apply survival analysis on the data of Czech companies and assess the impact of industry and type of business entity on corporate survival. According to the main findings, there is an association between all these factors and the probability of bankruptcy based on the used data sample. The main contribution to the current research is the application on real data of Czech companies, the study of selected factors on the probability of corporate survival and the comparison of estimated bankruptcy rates.
\end{abstract}

Keywords: Bankruptcy, Credit risk, Hazard function, Survival analysis.

JEL Classification: G21, G32, G33.

\section{Introduction}

The bankruptcy of companies is typically analysed on the basis of credit score models, which are statistically derived models for the prediction of credit risk. Among all the studies on scoring models, it is worth mentioning the study by Altman (1968) and the model known as the Altman's model or Z-score model. Since the first publication of this model, there has been an extensive research in the area of bankruptcy prediction and the application of methods such as discriminant analysis, logistic regression, classification trees or neural networks.

The approach of survival analysis can be seen as an alternative way to examine the survivor data, however, this area has not yet attracted an adequate attention compared to traditional methods as mentioned above. Nevertheless, there is a number of research studies that significantly contributes to the application of survival analysis for the prediction of corporate failure in different countries. For example, the earlier research includes the study by Lane et al. (1986) who employed the Cox model to predict bank failure, using a sample of 130 banks. As the author suggests, the overall accuracy of their model is similar to the results of

DOI: $10.24818 / 18423264 / 54.1 .20 .07$ 
the discriminant analysis. Among other studies, Laitinen and Kankaanpää (1999) discuss six most popular alternative methods to financial failure prediction, including survival analysis. The results of their study propose that there is no superior method even though the failure prediction accuracy varied depending on the prediction method applied. Other empirical results include for example the study by Agarwal and Audretsch (2001) who focus on the effect of companies' size on their survival. In their research, they find that smaller companies face a lower likelihood of survival when compared to larger companies. However, they suggest that general pronouncements are hazardous, because the role of the size changes over the industry cycle and with the technological demands of that industry. Similarly, Glennon and Nigro (2005) examined the effect of time on the probability of default of medium-maturity loans under a loan guarantee program of small firms. The authors find that the default behaviour of these loans is time sensitive, as a loan seasons, the probability of default initially increases and it then declines after the second year. They also suggest that the probability of default is conditional on borrower, lender, loan characteristics and changes in economic conditions. De Leonardis and Rocci (2008) used a discrete-time survival analysis approach for assessing the default risk of small and medium-sized Italian companies over the period 1995-1998. The authors suggest that the prediction accuracy of the duration model is better than that provided by a single-period logistic model.

In addition to examining the effect of financial and economic factors on corporate failure, there are studies that assess the impact of other factors. For example, Mokarami and Motefares (2013) examine the effect of the internal mechanisms of corporate governance on the bankruptcy of firms enlisted in Tehran Stock Exchange. Using the Cox model of survival analysis, the authors claim that there is a significant relationship between CEO replacement and bankruptcy. Another research include for example Pereira (2014) who applied the Cox proportion hazard model in predicting business failure of companies from the textile industry, or Kelly et al. (2015) who focused on corporate liquidations in Ireland. Louzada et al. (2014) modelled time to default on a personal loan portfolio and as they state in their article, due to the continuous monitoring of risk over time, survival models are being proposed in financial risk management as alternative tools. Their empirical study is illustrated on credit data from a Brazilian commercial bank and their results show that the attention should be paid to continuous checking of the validity of requirements for the use of the available models. Besides the problems of loan default and bankruptcy, Kristanti and Isynuwardhana (2018) examined the effect of certain predictors on the probability of financial distress of companies enlisted on the Indonesia Stock Exchange. Appling the Cox hazard model of survival analysis, they founded evidences that except for the predictors such as leverage, operational risk and size, there is an inverse relationship between the control of corruption and the probability of financial distress.

DOI: $10.24818 / 18423264 / 54.1 .20 .07$ 
Overall, there is a vast literature on the prediction of corporate bankruptcy using a variety of techniques, however there is still not much attention to the estimation of corporate bankruptcy using some methods. The aim of this article is to analyse survivor data of Czech companies and assess the impact of industry, type of business entity and business size on corporate survival using the methods of survival analysis. The main contribution to the current research is the application of survival analysis on real data of Czech companies, the examination of selected factors on the probability of corporate survival and the comparison of estimated bankruptcy rates. The analysis is conducted using the dataset of companies from different economic sectors for the period from 1988 - 2015. In this article, we focus on three hypotheses:

(i) The hypothesis that cyclical sectors such as construction or transportation are more risky and therefore corporate bankruptcy rates are higher when compared to other sectors.

(ii) The hypothesis that joint-stock companies are less risky than other types of business entities such as for example self-employers, foreign persons or cooperatives. This statement is based on the fact that joint-stock companies are typically companies that allow vast mobilisation of capital and its contribution to the expansion of business.

(iii) The hypothesis that smaller companies are more risky and tend to have a higher probability of bankruptcy. This premise is based on the assumption that smaller companies are more vulnerable to changes in the economic environment, especially during periods of economic contraction.

The structure of this article is as follows. Firstly, the used methodology is described and then the application on real data is conducted. The focus is paid to the impact of sector, type of entity and size on corporate bankruptcy. Finally, the main findings are summarised in the conclusion.

\section{Description of Methodology}

When the time to bankruptcy is considered as a dependent variable, we can predict survival, or non-bankruptcy corporate rates. For the purposes of the analysis of time to event, it is suggested to use the regression models that are appropriate for survivor data. As Hosmer et al. (2008, p. 3) state, the most important differences between the outcome variables modelled via linear and logistic regression analyses and the time variable is the fact that we may only observe the survival time partially. As Harrell (2010) points out, survival analysis is used to analyse the data in which the time until event is of interest. The survival analysis allows the response to be incompletely determined for some subjects, perhaps we are not able to follow all observations in the dataset. The analysis involves censoring mechanism, when we define the censored and uncensored observations. Hosmer et al. (2008, p. 18) define a censored observation as one whose value is incomplete due to random factors for each subject. If we analyse data using the survival procedure, the actual dates of start and finish times are not

DOI: 10.24818/18423264/54.1.20.07 
dealt with because they are different. Rather, we consider the length of time before the initial event, $t=0$, and the terminal event or date of the last information about the object, $t=1$ (Harrell, 2010). Based on the assumptions about the distribution of failure times, we can use nonparametric, semiparametric and parametric methods of survival analysis, which are in short described in his chapter. We focus on fundamental and basic theoretical background that can be supplement by a variety of publications for more details or specific issues as needed, for example Gourieroux and Jasiak (2007), Tabachnik and Fidell (2007), Hosmer et al. (2008), Cleves et al. (2010), Harrell (2010), Royston and Lambert (2011) or Klein et al. (2014).

\subsection{Survival and Hazard Functions}

In the case of right censoring, two random variables need to be defined, the survival time $\left(T_{\text {surv }}\right)$ and the censoring time $\left(\mathrm{T}_{\text {cens }}\right)$, where the censoring time is usually determined by the termination of the study. The crucial condition for statistical analysis is that survival time and censoring time are independent. According to Houwelingen and Stijnen (2014), the distribution function of the survival time is commonly called the failure function. For practical reasons, it is often more suitable to use a complimentary function in survival analysis, the survival function $S(t)$,

$$
\begin{gathered}
S(t)=1-F(t)=\operatorname{Pr}(T>t), \\
F(t)=\operatorname{Pr}(T \leq t),
\end{gathered}
$$

where $T$ is a nonnegative random variable denoting the time to a failure event and $F(t)$ refers to cumulative distribution. Thus, the survival function evaluated at time $t$ can be considered as the probability that a subject will live for at least time $t$, and it takes values between 0 and 1 . Using the survival function, we can estimate the probability of surviving beyond time $t$, or in other words, we can estimate the probability that there is no failure event prior to $t$. The density function $f(t)$ can be obtained both from $S(t)$ or $F(t)$ :

$$
f(t)=\frac{d F(t)}{d t}=\frac{d}{d t}\{1-S(t)\}=-S^{\prime}(t) .
$$

The hazard function or rate $h(t)$ at time $t$ can be explained as the probability that the subject will die, or more specifically the company will bankrupt, very shortly after reaching time $t$, provided that it reaches time $t$ (Gourieroux and Jasiak, 2007). Cleves et al. (2010) explain the hazard rate as the conditional failure rate or the intensity function. As they emphasize, the hazard rate represents the instantaneous rate of failure with $1 / t$ units: 


$$
h(t)=\lim _{\Delta t \rightarrow 0} \frac{\operatorname{Pr}(t+\Delta t>T>t \mid T>t}{\Delta t}=\frac{f(t)}{S(t)} .
$$

The hazard function can range from zero (no risk) to infinity (the certainty of failure at that instant) and can be decreasing, increasing, or constant, or it can even take on other different shapes. The relationship between the hazard and the survival function can be described as:

$$
h(t)=\frac{f(t)}{S(t)} .
$$

Gourieroux and Jasiak (2007) use the duration dependence to describe the relationship between the exit rate and the time spent in a given state by a subject. It is determined by the form of the hazard function. For example, the positive duration dependence in a sequence of failure events occurring randomly in time means that the more time elapsed since the last failure event, the greater the probability of an instantaneous occurrence of another failure. There are three types of duration dependence: negative, associated with decreasing hazard functions; positive, associated with increasing hazard functions, or there can be absence of duration dependence, when there is no relationship between the exit rate and the duration.

\subsection{Nonparametric Models}

According to Cleves et al. (2010), when no covariates exist or when they are qualitative in nature, we can use nonparametric methods such as Kaplan-Meier or Nelson-Aalen to estimate the probability of survival past a certain time or to compare survival experiences for different groups. The common characteristic of nonparametric models is that they do not make any assumptions neither about the distribution of failure times nor how covariates change the survival experience.

The Kaplan-Meier estimator of the survivorship function at time $t$ can be obtained from the equation

$$
\hat{S}(t)=\prod_{t_{(i)} \leq t} \frac{n_{i}-d_{i}}{n_{i}},
$$

where $n_{i}$ is the number at risk of dying (company failure) at $t_{(i)}, d_{i}$ refers to the observed number of deaths (company failures), and $\hat{S}(t)=1$ if $t<t_{(i)}$. If we assume that the time variable is absolutely continuous, then the survival function may be expressed as:

$$
S(t)=e^{-H(t)},
$$

DOI: 10.24818/18423264/54.1.20.07 
where $H(t)$, the cumulative hazard function, can be written as

$$
H(t)=-\ln (S(t)) .
$$

Aalen, Nelson and Altshuler proposed the indicator $H(t)$ that is referred to as Nelson-Aalen estimator (Hosmer et al., 2008). The Nelson-Aalen estimator of $H(t)$ is given by:

$$
\tilde{H}(t)=\sum_{t_{(i)} \leq t} \frac{d_{i}}{n_{i}},
$$

and the estimator of the survival function is

$$
\tilde{S}(t)=e^{-\tilde{H}(t)} .
$$

The function $H(t)$ is also called cumulative or integrated intensity process and can be defined as integral of the hazard from time 0 to time $t$,

$$
H(t)=\int_{0}^{t} h(u) d u,
$$

where $h()$ is the hazard function (Cleves et al., 2010; Hosmer et al., 2008). The Nelson-Aalen estimator of the hazard function at observed time $t$ can be written as:

$$
\tilde{h}\left(t_{i}\right)=\tilde{H}\left(t_{i+1}\right)-\tilde{H}\left(t_{i}\right)=\frac{d_{i}}{n_{i}} .
$$

As Hosmer et al. (2008) argue, the estimator in (12) requires a large number of failures at each point to be useful. Otherwise there is so much variability in the values that we are unable to draw any conclusions as to its base shape. However, the variability in the values can be smoothed out by the method of averaging, called kernel smoothing.

\section{Application to Corporate Survival}

For the purposes of the survival analysis, the data on companies were extracted from the BisnodeMagnusweb database and from the Czech government portal Justice.cz. The companies are observed during the period $1988-2015$ and the end of the study is March 15, 2015. The detailed description of data is provided in the next subchapter, followed by the Kaplan-Meier analysis, estimation of survival functions and comparison of bankruptcy rates.

\subsection{Data Description}

The sample comprises data of 16,733 subjects, including 1,163 bankruptcies considered as failure events. If the company did not bankrupt until the end of the study or if the company was not registered in the dataset any more, it is assumed to be a censored observation. Otherwise, the observation is uncensored. Each record in our data sample documents the time span of a particular company, 
The Impact of Industry and Business Entity Type on Corporate Survival

the original duration time is measured in days. The mean time to failure is $6,365.189$ days, 95\% [6,227.656, 6,402.722] based on 10,849 observations. Transferred to years, the average time to bankruptcy of all companies considered in our study is 17.4 years. The companies are grouped according to the following characteristics: Iindustry classification, business entity type and business size.

The survival analysis in the application part is conducted firstly for the overall sample and afterwards for all grouping categories. Thus, we can assess whether bankruptcy rates and the probability of survival are dependent on selected factors.

\section{a) Industry classification}

There are companies from nine industries ${ }^{1}$ considered in our dataset (Table 1). Construction and information technology are the most represented sectors, while the lowest number of firms comes from health care and water supply. Accordingly, the largest number of bankruptcies come from construction sector, followed by transportation and accommodation. Even this simple statistics suggests that construction might be the most risky industry. On the contrary, health care and water supply seem to be the less risky according to the relative number of failures.

Table 1.Description of industry groups

\begin{tabular}{|c|c|c|c|c|c|c|c|}
\hline Industry & Group & Sector & Code & $\begin{array}{c}\text { No. of } \\
\text { subjects }\end{array}$ & $\begin{array}{c}\text { No. of } \\
\text { subjects } \\
(\mathbf{\%})\end{array}$ & $\begin{array}{c}\text { No. of } \\
\text { events }\end{array}$ & $\begin{array}{c}\text { No. of } \\
\text { events } \\
(\mathbf{\%})\end{array}$ \\
\hline $\begin{array}{c}\text { Hotels, } \\
\text { restaurants, } \\
\text { leisure }\end{array}$ & $\mathbf{1}$ & Services & $\mathbf{1}$ & 1,906 & $11 \%$ & 161 & $13.8 \%$ \\
\hline $\begin{array}{c}\text { Diversified } \\
\text { consumer } \\
\text { services }\end{array}$ & $\mathbf{2}$ & Services & $\mathbf{1}$ & 2,060 & $12 \%$ & 104 & $8.9 \%$ \\
\hline Agriculture & $\mathbf{3}$ & Agriculture & $\mathbf{3}$ & 2,243 & $13 \%$ & 71 & $6.1 \%$ \\
\hline Construction & $\mathbf{4}$ & Industrials & $\mathbf{2}$ & 4,550 & $27 \%$ & 499 & $42.9 \%$ \\
\hline Entertainment & $\mathbf{5}$ & Services & $\mathbf{1}$ & 789 & $5 \%$ & 28 & $2.4 \%$ \\
\hline $\begin{array}{c}\text { Health care } \\
\text { equipment and } \\
\text { services }\end{array}$ & $\mathbf{6}$ & Services & $\mathbf{1}$ & 644 & $4 \%$ & 8 & $0.7 \%$ \\
\hline $\begin{array}{c}\text { IT services, } \\
\text { software }\end{array}$ & $\mathbf{7}$ & Services & $\mathbf{1}$ & 2,634 & $16 \%$ & 83 & $7.1 \%$ \\
\hline Transportation & $\mathbf{8}$ & Industrials & $\mathbf{2}$ & 1,228 & $7 \%$ & 181 & $15.6 \%$ \\
\hline Water supply & $\mathbf{9}$ & Utilities & $\mathbf{4}$ & 678 & $4 \%$ & 28 & $2.4 \%$ \\
\hline & Total & & $\mathbf{1 6 , 7 3 2}$ & $100 \%$ & $\mathbf{1 , 1 6 3}$ & $100 \%$ \\
\hline
\end{tabular}

b) Business entity type ${ }^{1}$ GICS - GlobalIndustryClassification Standard - MSCI (2019). https://www.msci.com/gics
(Accessed14.1.2019)

DOI: 10.24818/18423264/54.1.20.07 


\section{Martina Novotná}

Regarding the business entity type, or legal form, there are commercial companies and cooperatives in the Czech Republic that depend on factors such as the minimum number of founders, minimum registered capital or financial liability of members. The most common form of entrepreneurship in the Czech Republic is the limited-liability company ${ }^{2}$ which corresponds with the structure of our data sample, followed by joint-stock companies and cooperatives (Table 2). The least represented categories are unlimited and limited partnerships, European and foreign companies and foundations, referred to as Other in our analysis.

Table 2.Description of business entity type

\begin{tabular}{|c|c|c|c|c|c|}
\hline Legal form & Group & $\begin{array}{c}\text { No. of } \\
\text { subjects }\end{array}$ & $\begin{array}{c}\text { Rel.ve } \\
\text { frequency (\%) }\end{array}$ & $\begin{array}{c}\text { No. of } \\
\text { events }\end{array}$ & $\begin{array}{c}\text { Relative } \\
\text { frequency (\%) }\end{array}$ \\
\hline $\begin{array}{c}\text { Joint-stock } \\
\text { company }\end{array}$ & $\mathbf{1}$ & 2,265 & $14 \%$ & 138 & $11.9 \%$ \\
\hline Cooperative & $\mathbf{2}$ & 498 & $3 \%$ & 26 & $2.2 \%$ \\
\hline $\begin{array}{c}\text { Limited-liability } \\
\text { company }\end{array}$ & $\mathbf{3}$ & 13,790 & $82 \%$ & 995 & $85.6 \%$ \\
\hline Other & $\mathbf{4}$ & 182 & $1 \%$ & 4 & $0.3 \%$ \\
\hline \multicolumn{2}{|c|}{ Total } & 16,735 & $100 \%$ & $\mathbf{1 , 1 6 3}$ & $\mathbf{1 0 0 \%}$ \\
\hline
\end{tabular}

\section{c) Business size classification}

Enterprises are classified into different categories according to their size based on the OECD approach ${ }^{3}$. Overall, small and medium-sized enterprises employ less than 250 employees, while other companies are assumed to be large. The majority of companies included in our data sample are micro companies with less than 10 employees, followed by small and medium sized enterprises. Since the indicator of business size is not known for some companies, the total number of firms and events is lower when compared to the full sample size (Table 3).

Table 3.Description of business size groups

\begin{tabular}{|c|c|c|c|c|c|}
\hline Business class & Code & $\begin{array}{c}\text { No. of } \\
\text { subjects }\end{array}$ & $\begin{array}{c}\text { Relative } \\
\text { frequency (\%) }\end{array}$ & $\begin{array}{c}\text { No. of } \\
\text { events }\end{array}$ & $\begin{array}{c}\text { Relative } \\
\text { frequency (\%) }\end{array}$ \\
\hline Micro (0-9) & $\mathbf{1}$ & 7,410 & $53 \%$ & 388 & $45.5 \%$ \\
\hline Small (10-49) & $\mathbf{2}$ & 4,453 & $32 \%$ & 346 & $40.6 \%$ \\
\hline Medium (50-249) & $\mathbf{3}$ & 1,716 & $12 \%$ & 104 & $12.2 \%$ \\
\hline Large (>250) & $\mathbf{4}$ & 311 & $2 \%$ & 14 & $1.6 \%$ \\
\hline \multicolumn{2}{|c|}{ Total } & 13,890 & $100 \%$ & $\mathbf{8 5 2}$ & $\mathbf{1 0 0 \%}$ \\
\hline
\end{tabular}

\subsection{Empirical Results}

${ }^{2}$ BusinessInfo.cz (2019). Registrationoflegalformof business.

https://www.businessinfo.cz/en/psc/start-your-business/registration-of-legal-form-ofbusiness.html (Accessed18.1.2019)

${ }^{3}$ OECD (2019). Enterprises by business size (indicator).

https://data.oecd.org/entrepreneur/enterprises-by-business-size.htm(Accessed 18.1. 2019)

DOI: 10.24818/18423264/54.1.20.07 
The Impact of Industry and Business Entity Type on Corporate Survival

Kaplan-Meier (K-M) estimates are used to assess the corporate survival based on the equation (6). The overall K-M estimates of our data can be summarized using the table that shows the number of subjects at risk (eligible to fail), the number of fails, the number of lost observations, the estimate of survival function, standard error and confidence interval. Since there are totally 3,177 observed times, both fail or lost, it is not effective to exhibit the whole table of K$\mathrm{M}$ estimates in this article. Therefore, the K-M estimates are displayed for ten equally spaced time intervals (Table 4).

Table 4. K-M estimated at equally spaced time intervals

\begin{tabular}{|c|c|c|c|c|c|c|}
\hline Time & $\begin{array}{c}\text { No. at } \\
\text { risk }\end{array}$ & No. failed & $\begin{array}{c}\text { Survival } \\
\text { function }\end{array}$ & $\begin{array}{c}\text { Standard } \\
\text { error }\end{array}$ & \multicolumn{2}{|c|}{ [95\% Conf. Int.] } \\
\hline 18 & 16,733 & 0 & 1 &. &. &. \\
\hline 2,979 & 15,096 & 239 & 0.985 & 0.001 & 0.9830 & 0.9868 \\
\hline 5,940 & 7,839 & 570 & 0.9369 & 0.0022 & 0.9325 & 0.9411 \\
\hline 8,901 & 260 & 341 & 0.8482 & 0.0074 & 0.8331 & 0.8621 \\
\hline 11,862 & 170 & 7 & 0.8164 & 0.0138 & 0.7876 & 0.8417 \\
\hline 14,823 & 17 & 6 & 0.7823 & 0.0191 & 0.7421 & 0.8170 \\
\hline 17,784 & 15 & 0 & 0.7823 & 0.0191 & 0.7421 & 0.8170 \\
\hline 20,745 & 10 & 0 & 0.7823 & 0.0191 & 0.7421 & 0.8170 \\
\hline 23,706 & 2 & 0 & 0.7823 & 0.0191 & 0.7421 & 0.8170 \\
\hline 26,667 & 1 & 0 &. &. & &. \\
\hline
\end{tabular}

The equal time span is 2,961 days ( 8.11 years) and the survival function is calculated using all data in the dataset using formula (6). The function is undefined beyond 26,667 days because it is the largest observed time in the data sample. The estimated survival and cumulative hazard functions based on the whole data sample are shown in Figure 1.

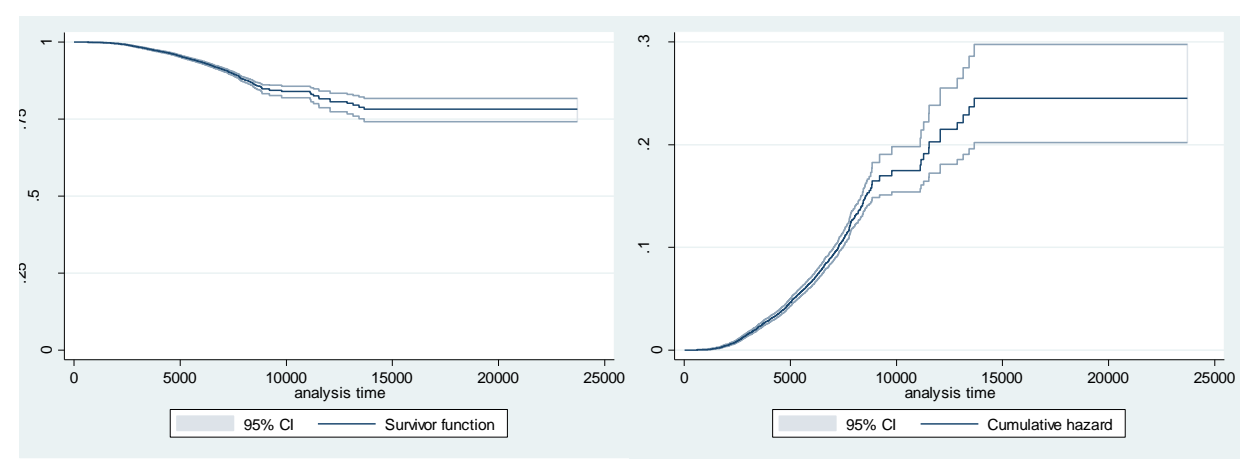

Figure 1.Survival and cumulative hazard function

a) The Effect of Industry

DOI: $10.24818 / 18423264 / 54.1 .20 .07$ 


\section{Martina Novotná}

Based on the mean estimated survival time (Table 5),transportation sector has the lowest estimated survival time, 8,148 days. The highest probability of failure of this sector can be associated with a high sensitivity on business cycle. In contrast, agriculture sector has the highest estimated survival time of 22,045 days, followed by consumer discretionary sectors such as hotels and restaurants and diversified consumer services.

Table 5. Estimated mean survival time by industry

\begin{tabular}{|c|c|c|c|c|c|}
\hline Group & Industry & Mean & $\begin{array}{c}\text { Standard } \\
\text { error }\end{array}$ & $\begin{array}{c}\text { Confidence interval } \\
(\mathbf{9 5 \%})\end{array}$ \\
\hline 1 & Hotels \& restaurants & $12,144.22$ & 252.7835 & $11,648.8$ & $12,639.7$ \\
\hline 2 & Consumer services & $14,764.29$ & 104.2735 & $14,559.9$ & $14,968.7$ \\
\hline 3 & Agriculture & $22,045.14$ & 266.2608 & $21,523.3$ & 22,567 \\
\hline 4 & Construction & $8,934.18$ & 48.3603 & $8,839.4$ & $9,028.96$ \\
\hline 5 & Entertainment & $8,842.45$ & 54.9133 & $8,734.82$ & $8,950.08$ \\
\hline 6 & Health care & $8,754.76$ & 25.7704 & $8,704.25$ & $8,805.27$ \\
\hline 7 & IT services \& SW & $8,981.86$ & 25.7090 & $8,931.47$ & $9,032.25$ \\
\hline 8 & Transportation & $8,148.01$ & 61.9625 & $8,026.56$ & $8,269.45$ \\
\hline 9 & Water supply & $11,426.56$ & 76.8639 & $11,275.9$ & $11,577.2$ \\
\hline \multicolumn{7}{|r|}{} & $20,258.08$ & 234.9081 & $19,797.7$ & $20,718.5$ \\
\hline
\end{tabular}

In order to provide more general results, some industries are combined together and we analyse four broader sectors: (1) services, (2) industrials, (3) agriculture and (4) utilities. The codes of these four sectors are denoted in Table 1. Among all sectors, the estimated survivorship of industrial companies is the lowest among all groups considered, followed by services, utility and agriculture. The tests of equality of overall survival functions across groups based on the log-rank test $\quad($ Chi2 $(3)=332.11)$, Wilcoxon $\quad($ Chi2 $(3)=266.71) \quad$ and Peto-Peto test (Chi2(3)=330.16) reject the hypothesis that the survival functions are the same (see Figure 2).

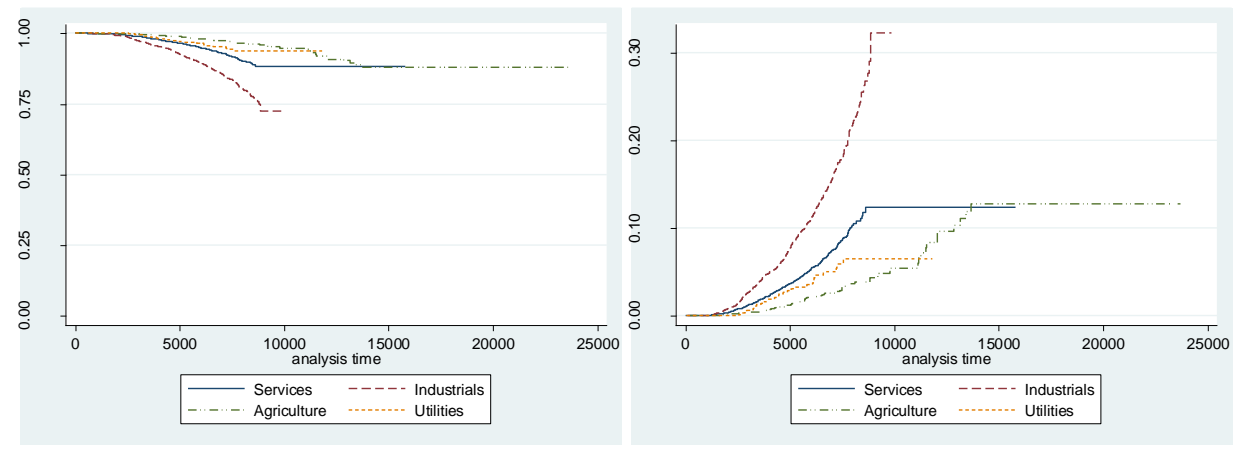

Figure 2. Survival and cumulative hazard functions by sector b) The Effect of Business Entity Type 
Considering the legal form, cooperatives have the highest estimated survival time, followed by joint-stock companies, limited liability companies and other legal forms (Table6).Since the majority of cooperatives traditionally and long-term operate in agriculture sector in the Czech Republic, these entities might be considered as less risky, which is consistent with our previous results on the effect of sector.

Table 6. Estimated mean survival time by business entity type

\begin{tabular}{|c|c|c|c|c|c|}
\hline Group & Legal status & Mean & $\begin{array}{c}\text { Standard } \\
\text { error }\end{array}$ & \multicolumn{2}{|c|}{$\begin{array}{c}\text { Confidence interval } \\
(95 \%)\end{array}$} \\
\hline 1 & Joint-stock company & $20,419.21$ & 383.0690 & $19,668.4$ & 21,170 \\
\hline 2 & Cooperative & $22,116.81$ & 313.4277 & $21,502.5$ & $22,731.1$ \\
\hline 3 & Limited-liability & $11,784.51$ & 76.7569 & $11,634.1$ & $11,934.9$ \\
\hline 4 & Other & $9,005.02$ & 60.7944 & $8,885.9$ & $9,124.2$ \\
\hline & Total & $20,258.2$ & 234.9092 & $19,797.8$ & $20,718.6$ \\
\hline
\end{tabular}

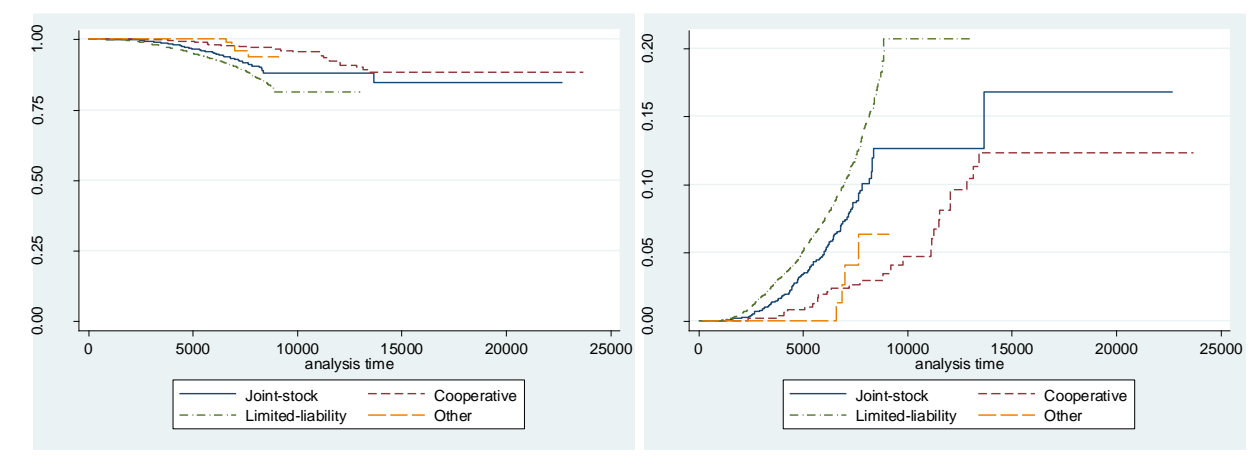

Figure 3. Survival and cumulative hazard functions by business entity type

The tests of equality of overall survival functions across groups based on the log-rank test $(\mathrm{Chi} 2(3)=65.55)$, Wilcoxon $(\mathrm{Chi} 2(3)=55.37)$ and Peto-Peto test $($ Chi2 $(3)=65.73)$ reject the hypothesis that the survival functions are the same (see Figure 3).

c) The Effect of Business Size

The estimated mean survival time of micro companies is lower than the estimated mean of small companies (Table7), however small companies have a higher cumulative hazard rate between 2,317 - 12,868 days of their age. The estimated mean survival time of medium companies is similar to large companies (multiple survival and cumulative hazard functions by business size are shown in Figure 4). The visual results suggest that the lowest probability of survival have micro and small companies.

Table 7. Estimated mean survival time by size

DOI: 10.24818/18423264/54.1.20.07 


\begin{tabular}{|c|c|c|c|c|c|}
\hline Group & $\begin{array}{c}\text { Business } \\
\text { category }\end{array}$ & Mean & $\begin{array}{c}\text { Standard } \\
\text { error }\end{array}$ & \multicolumn{2}{|c|}{$\begin{array}{c}\text { Confidence interval } \\
\mathbf{( 9 5 \% )}\end{array}$} \\
\hline 1 & Micro & $17,685.26$ & 423.9196 & $16,854.4$ & $18,516.1$ \\
\hline 2 & Small & $20,602.77$ & 199.7884 & $20,211.2$ & $20,994.4$ \\
\hline 3 & Medium & $21,676.40$ & 226.4600 & $21,232.5$ & $22,120.3$ \\
\hline 4 & Large & $21,952.62$ & 633.8178 & $20,710.4$ & $23,194.9$ \\
\hline \multicolumn{2}{r}{ Total } & $21,138.63$ & 165.0586 & $20,815.1$ & $21,462.1$ \\
\hline
\end{tabular}

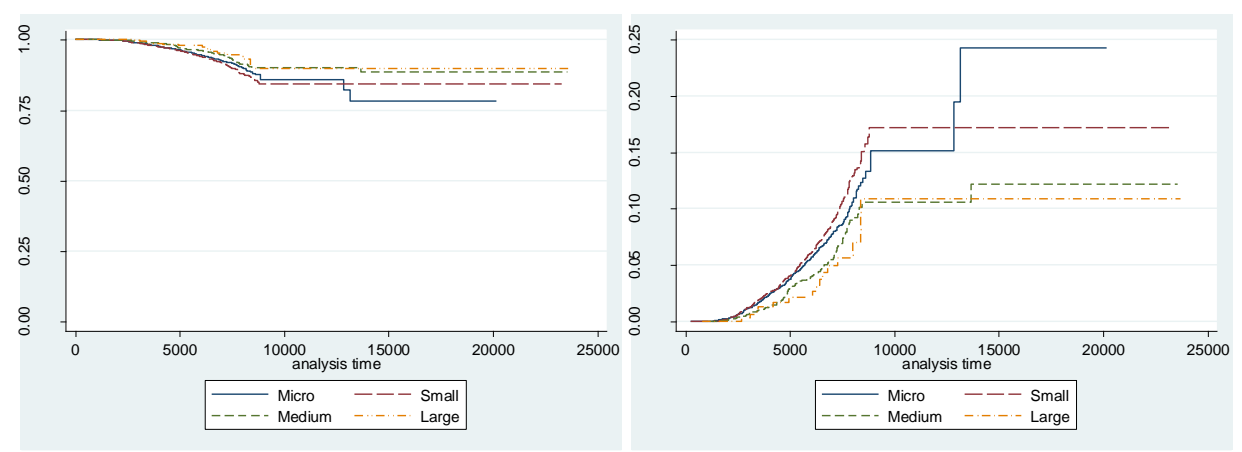

Figure 4. Survival and cumulative hazard functions by business size

The tests of equality of overall survival functions across groups based on the log-rank test $(\mathrm{Chi} 2(3)=17.24)$, Wilcoxon $(\mathrm{Chi} 2(3)=15.61)$ and Peto-Peto test (Chi2(3)=17.31) reject the hypothesis that the survival functions are the same (see Figure 4).

\subsection{Comparison of Corporate Bankruptcy Rates}

To compare the average credit quality of all companies used in our analysis, we compare the cumulative bankruptcy rates (CBR) calculated at the end of each year. Corporate bankruptcy rates by industry, business entity type and size are summarized in Appendix (Tables A - C). For example, while a 5-year average cumulative bankruptcy rate of service sector companies is $0.23 \%$, it is $0.58 \%$ for industrials. Similarly, a 15 -year bankruptcy rate is $4.2 \%$ for services and $8.91 \%$ for industrials. The bankruptcy rates at each year supplement our previous findings and provide a practical tool for an average assessment of corporate credit risk according to the grouping criteria used in the analysis. The visual comparison of corporate bankruptcy rates at the end of each year can be seen in Figure 5. 


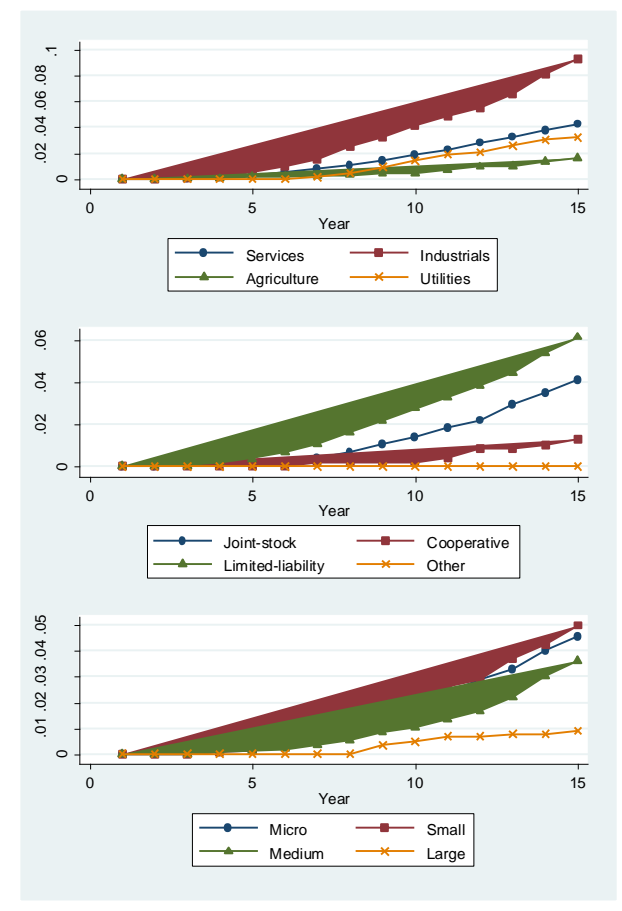

Figure 5.Comparison of bankruptcy rates

\section{Conclusion}

The study of corporate bankruptcy and the prediction of bankruptcy rates can be considered as an important part of individual credit risk analysis. There is a variety of methods that are suitable for modelling corporate bankruptcy, from traditional to more sophisticated approaches. Survival analysis is an alternative way to examine survivor data and the relationship between a time variable and the probability of failure. The main purpose of this article was to apply survival analysis on the data of Czech companies and examine the impact of economic sector, business entity type and business size on the probability of bankruptcy.

The empirical results provide evidence that there is an association between all these factors and the probability of bankruptcy based on the used data. To summarize, we conclude that micro companies from transportation sector formed as limited-liability companies belong to the most risky subjects in our study. On the opposite side, larger companies from agricultural sector formed as cooperatives can be considered as less risky form of business in the Czech Republic. More generally, industrial companies tend to be more risky than services, utility and agriculture. Cooperatives and joint-stock companies, mostly privately held, have the highest estimated survival time compared to limited-liability companies and

DOI: 10.24818/18423264/54.1.20.07 
other forms. Regarding the size of the company, the main findings suggest that the lower the number of employees, the lower the probability of survival.

To summarise, this article provided an alternative perspective on the measurement and prediction of firm-based credit risk. Whentaking into account the length of time before bankruptcy, the survival analysis is a suitable method for modelling the data. Thus, using this method is appropriate for the purposes of financial and risk management. For example, the analysis of time to default, which is conducted by credit rating agencies, is based on cumulative distribution of defaulters by time of default and survival rates.

The knowledge of corporate survival over some period might help investors and lenders access the credit quality of borrowers and predict potential problems of default, insolvency or bankruptcy. The main findings of this study can be used by creditors, financial managers or risk analytics in order to make financial decisions or prevent financial losses in the event of corporate bankruptcy.

\section{ACKNOWLEDGEMENTS}

This paper was supported by the Operational Programme for Competitiveness under Project CZ.1.07/2.3.00/20.0296 and Project SGS 2019/132.

\section{REFERENCES}

[1]Agarwal, R., Audretsch, D. B. (2001), Does Entry Size Matter? The Impact of the Life Cycle and Technology on Firm Survival. The Journal of Industrial Economics, 49(1): 21-43;

[2]Altman, E. I. (1968), Financial Ratios, Discriminant Analysis and the Prediction of Corporate Bankruptcy. Journal of Finance, 23(4): 189-209;

[3]Cleves, M. A. et al. (2010),An Introduction to Survival Analysis Using Stata. College Station: Stata Press;

[4]De Leonardis, D., Rocci, R. (2008), Assessing the Default Risk by Means of a Discrete-time Survival Analysis Approach.Applied Stochastic Models in Business and Industry, 24: 291-306;

[5]Glennon, D., Nigro, P. (2005), Measuringthe Default Risk ofSmall Business Loans: A SurvivalAnalysisApproach. Journal ofmoneycredit and banking, 37(5):923-47;

[6]Gourieroux, Ch., Jasiak, J. (2007), Econometrics of Individual Risk: Credit, Insurance and Marketing. Princenton: Princeton University Press;

[7]Harrell, F. E. (2010), Regression Modeling Strategies: with Applications to Linear Models, Logistic Regression, and Survival Analysis. New York: Springer; [8]Hosmer, D. W., Lemeshow, S., May, S. (2008), Applied Survival Analysis: Regression Modeling of Time-to-Event Data. Hoboken:John Wiley \& Sons; 
The Impact of Industry and Business Entity Type on Corporate Survival

[9]Kelly, R., Brien, E. O., Stuart, R. (2015), A Long-Run Survival Analysis of Corporate Liquidations in Ireland. Small Business Economics, 44: 671-683;

[10] Klein, J. P., Houwelingen, J. C., Ibrahim, J. G., Scheike, T. H. ed. (2014),Handbook of Survival Analysis. Boca Raton: CRC Press, Taylor \& Francis Group;

[11] Kristanti, F. T., Isynuwardhana, D. (2018), Survival Analysis of Industrial Sectors in Indonesia Companies. JurnalKeuangandanPerbankan, 22(1): 23-36;

[12] Laitinen, T., Kankaanpää, M. (1999),Comparative Analysis of Failure

Prediction Methods: The Finnish Case. The European Accounting Review, 8(1):

67-92;

[13] Lane, W., Looney, S., Wansley, J. (1986), An Application of the Cox

Proportional Hazards Model to Bank Failure. Journal of Banking and Finance, 10: 511-531;

[14] Louzada, F., Cancho, V. D., Oliveira, M. R., Bao, Y. (2014), Modeling Time to Default on a Personal Loan Portfolio in Presence of Disproportionate Hazard Rates.Journal of Statistics Applications \& Probability, 3(3): 1-11; [15] Mokarami, M., Motefares, Z. (2013),Corporate Governance and PredictingBankruptcyof FirmsUsingSurvivalAnalysis(Case Studyof Companies Listed in TehranStock Exchange). Life Science Journal, 10(1): 1089-1095; [16] Pereira, J. (2014),Survival Analysis Employed in Predicting Corporate Failure: A Forecasting Model Proposal. International Business Research, 7(5): 9-20;

[17] Royston, P. (2006),Explained Variation for Survival Models. The Stata Journal, 6(1): 83-96;

[18] Tabachnik, B. G., Fidell, L. S. (2007),Using Multivariate Statistics. Boston: Pearson Allyn\& Bacon.

Appendix: Comparison of Corporate Bankruptcy Rates

\begin{tabular}{|c|c|c|c|c|}
\hline Years & 1 & 2 & 3 & 4 \\
\hline 1 & $0.00 \%$ & $0.00 \%$ & $0.00 \%$ & $0.00 \%$ \\
\hline 2 & $0.04 \%$ & $0.00 \%$ & $0.00 \%$ & $0.00 \%$ \\
\hline 3 & $0.06 \%$ & $0.02 \%$ & $0.04 \%$ & $0.00 \%$ \\
\hline 4 & $0.15 \%$ & $0.18 \%$ & $0.04 \%$ & $0.00 \%$ \\
\hline 5 & $0.23 \%$ & $0.58 \%$ & $0.14 \%$ & $0.00 \%$ \\
\hline 6 & $0.49 \%$ & $0.95 \%$ & $0.18 \%$ & $0.00 \%$ \\
\hline 7 & $0.77 \%$ & $1.49 \%$ & $0.27 \%$ & $0.15 \%$ \\
\hline 8 & $1.06 \%$ & $2.44 \%$ & $0.32 \%$ & $0.46 \%$ \\
\hline 9 & $1.45 \%$ & $3.20 \%$ & $0.41 \%$ & $0.92 \%$ \\
\hline 10 & $1.85 \%$ & $4.09 \%$ & $0.46 \%$ & $1.39 \%$ \\
\hline 11 & $2.28 \%$ & $4.74 \%$ & $0.70 \%$ & $1.88 \%$ \\
\hline 12 & $2.81 \%$ & $5.33 \%$ & $0.96 \%$ & $2.06 \%$ \\
\hline 13 & $3.23 \%$ & $6.39 \%$ & $1.01 \%$ & $2.59 \%$ \\
\hline 14 & $3.72 \%$ & $7.85 \%$ & $1.33 \%$ & $2.98 \%$ \\
\hline 15 & $4.20 \%$ & $8.91 \%$ & $1.62 \%$ & $3.18 \%$ \\
\hline
\end{tabular}

Table A. Corporate bankruptcy rates by industry

DOI: 10.24818/18423264/54.1.20.07 
Martina Novotná

\begin{tabular}{|c|c|c|c|c|}
\hline Years & 1 & 2 & 3 & 4 \\
\hline 1 & $0.00 \%$ & $0.00 \%$ & $0.00 \%$ & $0.00 \%$ \\
\hline 2 & $0.00 \%$ & $0.00 \%$ & $0.02 \%$ & $0.00 \%$ \\
\hline 3 & $0.04 \%$ & $0.00 \%$ & $0.04 \%$ & $0.00 \%$ \\
\hline 4 & $0.09 \%$ & $0.00 \%$ & $0.16 \%$ & $0.00 \%$ \\
\hline 5 & $0.18 \%$ & $0.00 \%$ & $0.37 \%$ & $0.00 \%$ \\
\hline 6 & $0.27 \%$ & $0.00 \%$ & $0.67 \%$ & $0.00 \%$ \\
\hline 7 & $0.40 \%$ & $0.20 \%$ & $1.06 \%$ & $0.00 \%$ \\
\hline 8 & $0.67 \%$ & $0.20 \%$ & $1.61 \%$ & $0.00 \%$ \\
\hline 9 & $1.04 \%$ & $0.20 \%$ & $2.13 \%$ & $0.00 \%$ \\
\hline 10 & $1.37 \%$ & $0.20 \%$ & $2.72 \%$ & $0.00 \%$ \\
\hline 11 & $1.81 \%$ & $0.41 \%$ & $3.23 \%$ & $0.00 \%$ \\
\hline 12 & $2.17 \%$ & $0.82 \%$ & $3.76 \%$ & $0.00 \%$ \\
\hline 13 & $2.92 \%$ & $0.82 \%$ & $4.37 \%$ & $0.00 \%$ \\
\hline 14 & $3.48 \%$ & $1.04 \%$ & $5.27 \%$ & $0.00 \%$ \\
\hline 15 & $4.03 \%$ & $1.26 \%$ & $5.97 \%$ & $0.00 \%$ \\
\hline
\end{tabular}

Table B. Corporate bankruptcy rates by business entity type

\begin{tabular}{|c|c|c|c|c|}
\hline Years & 1 & 2 & 3 & 4 \\
\hline 1 & $0.00 \%$ & $0.00 \%$ & $0.00 \%$ & $0.00 \%$ \\
\hline 2 & $0.00 \%$ & $0.00 \%$ & $0.00 \%$ & $0.00 \%$ \\
\hline 3 & $0.01 \%$ & $0.00 \%$ & $0.00 \%$ & $0.00 \%$ \\
\hline 4 & $0.08 \%$ & $0.05 \%$ & $0.06 \%$ & $0.00 \%$ \\
\hline 5 & $0.19 \%$ & $0.14 \%$ & $0.12 \%$ & $0.00 \%$ \\
\hline 6 & $0.36 \%$ & $0.38 \%$ & $0.18 \%$ & $0.00 \%$ \\
\hline 7 & $0.66 \%$ & $0.63 \%$ & $0.35 \%$ & $0.00 \%$ \\
\hline 8 & $1.11 \%$ & $1.09 \%$ & $0.53 \%$ & $0.33 \%$ \\
\hline 9 & $1.39 \%$ & $1.58 \%$ & $0.82 \%$ & $0.65 \%$ \\
\hline 10 & $1.87 \%$ & $2.06 \%$ & $1.00 \%$ & $1.33 \%$ \\
\hline 11 & $2.36 \%$ & $2.55 \%$ & $1.31 \%$ & $1.33 \%$ \\
\hline 12 & $2.83 \%$ & $2.84 \%$ & $1.63 \%$ & $1.70 \%$ \\
\hline 13 & $3.24 \%$ & $3.61 \%$ & $2.16 \%$ & $1.70 \%$ \\
\hline 14 & $3.95 \%$ & $4.13 \%$ & $2.98 \%$ & $2.12 \%$ \\
\hline 15 & $4.45 \%$ & $4.85 \%$ & $3.55 \%$ & $2.12 \%$ \\
\hline
\end{tabular}

Table C. Corporate bankruptcy rates by size 